\title{
Editorial
}

\section{Comparing minimally invasive, hybrid, and open surgical techniques for adult spinal deformity}

\author{
Alexander Tuchman, M.D., ${ }^{1}$ And Patrick C. Hsieh, M.D. ${ }^{1,2}$
}

${ }^{1}$ Department of Neurological Surgery, University of Southern California Keck School of Medicine; and ${ }^{2}$ USC Spine Center, Keck Medical Center of USC, Los Angeles, California

Adult spinal deformity (ASD) is a rapidly advancing field in terms of understanding the pathophysiology and available surgical treatments. Traditionally, radiographic correction of coronal and sagittal global balance has correlated with improvement in clinical outcomes and is the primary goal in ASD surgery. ${ }^{6,7}$ Recent clinical outcomes-driven research has revealed that correcting sagittal balance and pelvic tilt significantly improves patient outcomes. ${ }^{10,12,13}$ Meanwhile, coronal imbalance has a considerably lesser effect on functional disability in the adult population. ${ }^{4,6,7}$ Understanding the clinical issues that correlate with improved health-related quality of life indices allows the surgeon to tailor his or her treatment plan to best address the symptomatic pathology while minimizing patient risk. Despite the demonstrated efficacy of ASD surgery, traditional open surgical treatments carry significant patient risk with an approximately $40 \%$ overall complication rate. ${ }^{3,4,17}$

Deformity principles have expanded our consideration of spine disease to the macro level. For example, we now understand that when evaluating lumbar disease, we must be cognizant of the compensatory response required of the cervical and thoracic spine as well as the pelvis in order to maintain global alignment. In apparent contradistinction, surgical techniques in spine surgery have been trending towards more minimally invasive methods over the past 2 decades. Minimally invasive spine surgery techniques generally cause less "collateral damage" resulting in decreased blood loss, lower infection rates, quicker recovery, and shorter hospital stays. ${ }^{5,8,9,11}$ Unfortunately, minimally invasive and open spine deformity surgeries have largely remained as two distinct subspecialties in spine surgery, with few surgeons who consider themselves proficient in both disciplines. Thus, until recently, the principles of minimally invasive surgery (MIS) were rarely applied to the treatment of ASD. The benefits of minimally invasive techniques (that is, MIS vs open transforaminal lumbar interbody fusion) have been demonstrated for degenerative disease over a short segment of the spine. , $, 8,9$ However, the indications, efficacy, and complications of minimally invasive techniques when applied to the treatment of spinal deformity have not been adequately compared with open procedures.

Uribe et al. ${ }^{14}$ are to be commended for comparing and describing the complication rates associated with open, MIS, and hybrid deformity correction methods while attempting to control for patient factors. Any study that endeavors to compare surgical techniques in an observational fashion will have biases from the clinical factors that compelled the surgeon to use a particular approach in the first place. The authors used propensity score matching to create a subpopulation within their database of 280 patients with spinal deformity who had similar preoperative variables. Their method resulted in a cohort of 60 patients to compare evenly split MIS, hybrid, and open groups.

Creating the cohort using this method led to two significant limitations in the study. First, any reasoning that takes into account factors beyond age, preoperative sagittal vertebral axis (SVA), number of levels fused posteriorly, and lumbar coronal Cobb angle in deciding surgical approach are not accounted for. This creates biases among the groups because of unobserved or unaccounted for covariates. Important influences, such as body mass index, comorbidities, previous surgeries, or experience of the operating surgeon, were not included in the propensity matching and thus may taint any conclusions drawn from the assumed preoperatively equivalent populations. Second, the 60 patients who were compared had relatively well-compensated sagittal alignment with an average SVA of $2.8,6.1$, and $6.8 \mathrm{~cm}$ in the MIS, hybrid, and open groups, respectively. These subgroups are not truly representative examples of the symptomatic ASD population as a whole, making conclusions from this study pertinent only to those patients with mild to moderate deformity.

The MIS group in the authors' study had a significantly lower rate of intraoperative complications than the hybrid and open groups. The authors attributed this to an increased rate of excessive blood loss in the open group. The rates of total, postoperative, major, and minor complications were all lowest in the MIS group, but the study was too underpowered to show statistical significance. Moreover, with only 1 year of follow-up, the study is not suited to address questions about long-term complications such as proximal junctional kyphosis, pseudarthrosis, and implant failure. In fact, the authors already reported an $8 \%$ rate of implant failure as the most frequent complication in the MIS group at the latest follow-up. 
Although the radiographic parameters for the 3 groups were similar, the overall trend of the results seemed to favor open or hybrid procedures for sagittal correction. The results make intuitive sense, as the open and hybrid procedures allow for more extensive bony osteotomies, the most powerful tool for sagittal realignment. The MIS and hybrid groups used more interbody grafts, probably contributing to the significant coronal correction. This pattern of improved coronal deformity with more modest effects on sagittal alignment accords with the results of previous evaluations of minimally invasive lateral interbody fusions for deformity correction. . $^{1,2,15,16}$

New MIS and hybrid techniques, such as anterior column realignment, are being developed and applied to spinal deformity surgery more commonly. As these newer procedures continue to gain momentum and acceptance in the spine surgery community, proficiency in a variety of techniques will be crucial to individualizing treatment according to the specific pathophysiology in each patient. The potential to achieve the common goal of restoring global sagittal and coronal balance in ASD surgery while minimizing surgery-related morbidity via minimally invasive techniques is extremely appealing. The study by Uribe et al. shows a positive trend in favoring minimally invasive or hybrid surgical treatment of ASD over open techniques. However, the study is retrospective and somewhat underpowered to demonstrate improved clinical and radiographic outcomes with statistical significance. Future prospective control studies are much needed to determine if we can truly achieve the essential radiographic and clinical outcomes of spinal deformity surgery through minimally invasive techniques to reduce complication rates.

(http://thejns.org/doi/abs/10.3171/2014.3.FOCUS14113)

\section{Disclosure}

The authors report no conflict of interest.

\section{References}

1. Acosta FL, Liu J, Slimack N, Moller D, Fessler R, Koski T: Changes in coronal and sagittal plane alignment following minimally invasive direct lateral interbody fusion for the treatment of degenerative lumbar disease in adults: a radiographic study. Clinical article. J Neurosurg Spine 15:92-96, 2011

2. Anand N, Baron EM, Khandehroo B, Kahwaty S: Long-term 2- to 5-year clinical and functional outcomes of minimally invasive surgery for adult scoliosis. Spine (Phila Pa 1976) 38: $1566-1575,2008$

3. Charosky S, Guigui P, Blamoutier A, Roussouly P, Chopin $\mathrm{D}$ : Complications and risk factors of primary adult scoliosis surgery: a multicenter study of 306 patients. Spine (Phila Pa 1976) 37:693-700, 2010

4. Daubs MD, Lenke LG, Cheh G, Stobbs G, Bridwell KH: Adult spinal deformity surgery: complications and outcomes in patients over age 60. Spine (Phila Pa 1976) 32:2238-2244, 2007

5. Dhall SS, Wang MY, Mummaneni PV: Clinical and radiographic comparison of mini-open transforaminal lumbar interbody fusion with open transforaminal lumbar interbody fusion in 42 patients with long-term follow-up. Clinical article. J Neurosurg Spine 9:560-565, 2008

6. Glassman SD, Berven S, Bridwell K, Horton W, Dimar JR: Correlation of radiographic parameters and clinical symptoms in adult scoliosis. Spine (Phila Pa 1976) 30:682-688, 2005

7. Glassman SD, Bridwell K, Dimar JR, Horton W, Berven S, Schwab F: The impact of positive sagittal balance in adult spinal deformity. Spine (Phila Pa 1976) 30:2024-2029, 2005

8. Khoo LT, Fessler RG: Microendoscopic decompressive laminotomy for the treatment of lumbar stenosis. Neurosurgery 51 (5 Suppl):S146-S154, 2002

9. Khoo LT, Palmer S, Laich DT, Fessler RG: Minimally invasive percutaneous posterior lumbar interbody fusion. Neurosurgery 51 (5 Suppl):S166-S171, 2002

10. Lafage V, Schwab F, Patel A, Hawkinson N, Farcy JP: Pelvic tilt and truncal inclination: two key radiographic parameters in the setting of adults with spinal deformity. Spine (Phila Pa 1976) 34:E599-E606, 2009

11. O'Toole JE, Eichholz KM, Fessler RG: Surgical site infection rates after minimally invasive spinal surgery. Clinical article. J Neurosurg Spine 11:471-476, 2009

12. Schwab F, Patel A, Ungar B, Farcy JP, Lafage V: Adult spinal deformity-postoperative standing imbalance: how much can you tolerate? An overview of key parameters in assessing alignment and planning corrective surgery. Spine (Phila Pa 1976) 35:2224-2231, 2010

13. Schwab FJ, Blondel B, Bess S, Hostin R, Shaffrey CI, Smith JS, et al: Radiographical spinopelvic parameters and disability in the setting of adult spinal deformity: a prospective multicenter analysis. Spine (Phila Pa 1976) 38:E803-E812, 2013

14. Uribe JS, Deukmedjian AR, Mummaneni PV, Fu KMG, Mundis GM Jr, Okonkwo DO, et al: Complications in adult spinal deformity surgery: an analysis of minimally invasive, hybrid, and open surgical techniques. Neurosurg Focus 36(5):E15, 2014

15. Wang MY: Less invasive mini-open adult spinal deformity surgery. Neurosurg Focus 35 (2 Suppl):Video 1, 2013

16. Wang MY, Mummaneni PV: Minimally invasive surgery for thoracolumbar spinal deformity: initial clinical experience with clinical and radiographic outcomes. Neurosurg Focus 28(3):E9, 2010

17. Yadla S, Maltenfort MG, Ratliff JK, Harrop JS: Adult scoliosis surgery outcomes: a systematic review. Neurosurg Focus 28(3):E3, 2010

Please include this information when citing this paper: DOI: 10.3171/2014.3.FOCUS14113. 